Original article

\title{
CYTOKINES AND IMMUNOGLOBULIN G RESPONSE IN DONKEYS WITH SPONTANEOUS SETARIA EQUINA INFECTION
}

\author{
A. H. EL NAMAKY, S. H. HENDAWY, F. A. ABO-AZIZA \& H. M. ASHRY \\ Department of Parasitology and Animal Diseases, National Research Centre, \\ Giza, Egypt
}

\begin{abstract}
Summary
El Namaky, A. H., S. H. Hendawy, F. A. Abo-Aziza \& H. M. Ashry, 2019. Cytokines and immunoglobulin G response in donkeys with spontaneous Setaria equina infection. Bulg. J. Vet. Med., 22, No 2, 180-189.

Setaria equina (S. equina) is a filarial worm that exists in peritoneal cavity of equines. This study aimed to evaluate cytokine mediators tumour necrosis factor alpha (TNF- $\alpha$ ), interleukin-4 (IL-4) and immunoglobulin $\mathrm{G}(\mathrm{IgG})$ responses in spontaneously S. equina infected and non-infected donkeys with emphasis on choosing the best antigen that could be used in diagnosis of such filarial infection. A total of 87 donkeys were examined. Two S. equina antigens: crude somatic $S$. equina antigen (CSS) and excretory secretory $S$. equina antigen (ESS) were prepared. They were evaluated in diagnosis of the infection using indirect ELISA and electrophoretically characterised through sodium dodecyl sulphate poly acrylamide gel electrophoresis (SDS-PAGE) and western blotting technique. The results indicated that both TNF- $\alpha$ and IL- 4 in the serum of infected donkeys were significantly higher compared with the non-infected group at $\mathrm{P}<0.05$ and $\mathrm{P}<0.01$, respectively. However, the IL- 4 level of infected donkeys was significantly higher than that of TNF- $\alpha(\mathrm{P}<0.01)$. Apparent prevalence, specificity and positive predictive values $(96.55 \%, 100 \%$, and $100 \%$ each) of CSS showed higher diagnostic accuracy than that of ESS. In addition, electrophoretic protein profile and IgG reactivity of CSS antigen via western blot presented a prominent reactive protein band at $28 \mathrm{kDa}$. It was concluded that the CSS antigen was the best antigen that could be used in serodiagnosis of $S$. equina infection. The cytokine responses were explored in order to differentiate infected from non-infected donkeys.
\end{abstract}

Key words: cytokines, diagnosis, immunoglobulin G, Setaria equina

\section{INTRODUCTION}

S. equina is one of the several filarial nematodes affecting equines worldwide (Bahgat et al., 2011). A high incidence of infection is recorded by several surveys all over the world including Egypt (Mahmoud, 1998; Hornok et al., 2008; Sulei- man et al., 2012). The incidence of this filarial nematode is revealed in both the definitive (equines) and the intermediate (mosquitoes) hosts (Bahgat et al., 2011). The adult forms usually reside floating freely in the peritoneal cavity and occa- 
sionally lodged in erratic habitat such as the pleural cavity, eye, brain, spinal medulla and testicles of the horse (Solusby, 1982; Marzok \& Desouky, 2009). Larvae produced by adult worms in the peritoneal cavity reach the circulation and are taken up by mosquito species. Infective larvae develop in the mosquito flight muscle and are reinjected into hosts when the mosquitoes feed. In most cases, adult stages are considered non-pathogenic but may cause various degrees of fibrinous peritonitis (Rhee et al., 1994; Mahmoud, 1998), whereas the serious pathogenic effect of $S$. equina occurs when the microfilariae migrate erratically into unusual habitats in the host such as the ocular globe or central nervous system (Hillyer et al., 2001).

Traditionally, the Knott technique is a common diagnostic procedure that depends on detection of microfilaria in peripheral blood of infected equines (Suleiman et al., 2012). Although identification of filarial parasite in blood is acknowledged, today accurate diagnosis is crucial for the effective treatment and successful eradication of the disease. Accurate diagnosis is dependent on the clinical condition of the host to distinguish between active and past infection. Recently, early diagnosis of such infection has been associated with concurrent release of cytokine mediators. Since filarial infections are chronic, many research studies have focused on the $\mathrm{T}$ and $\mathrm{B}$ cell adaptive immune response (Kwarteng et al., 2016). T helper (Th) cells from the majority of $\mathrm{T}$ lymphocyte responses and following activation differentiate into effector Th1 and Th2 which are associated with the development of type- 2 cytokines immune response and impairment of type1 cytokine production (Wammes et al., 2012; Kwarteng et al., 2016). Increased levels of IL-4, IL-5 and IL-10 were re- ported in all chronic, microfilaraemic and endemic control cases while a significant decrease was observed in IL-2 and IFN $\gamma$ levels in microfilaraemic patients as compared to chronic and endemic control cases (Sharma et al., 2005; Wammes et al., 2012). In addition, detection of antifilarial antibodies against purified and crude antigens in the sera of infected equines is also a tool for diagnosis. Hence, detection of total anti-filarial IgG antibody is effective in the diagnosis of latent infections (Njenga et al., 2007; Simonsen et al., 2008). The release of macromolecules such as excretory-secretory antigens and somatic sheath cells by living adult filarial nematodes into their surroundings induce higher antibody titres that are capable of modulating the immune responses (Kaushal et al., 1984; Tizard, 2000). An accurate diagnostic technique has to be reliable and reproducible thus focusing on characterisation and determination of potential immunodiagnostic antigens using sodium dodecyl sulphate polyacrylamide gel electrophoresis (SDS-PAGE) and western blotting techniques along with a reliable immunoassay technique such as indirect enzyme linked immunosorbent assay (ELISA) (Mohanty et al., 2006; Kaushal et al., 2009; Abdel-Latif \& Sakran, 2016).

Our research goal was to investigate the significance of cytokines and total IgG response in $S$. equina infected donkeys with emphasis on most immunogenic antigen chosen by SDS-PAGE and immunoblotting techniques that could be used in sero-diagnosis of such infection.

\section{MATERIALS AND METHODS}

Animals and samples collection

A total of 87 donkeys were slaughtered at Giza zoo's abattoir between November 
2015 and March 2016. Blood samples were collected from the animals, sera were separated by centrifugation for 10 min at $3000 \mathrm{rpm}$ (Sigma-202c, Germany) and stored at $-20{ }^{\circ} \mathrm{C}$ for cytokines and IgG analysis. All institutional and national guidelines for the care and use of animals were followed.

\section{Parasite and antigen preparation}

At necropsy, the peritoneal cavity and its fluid from all slaughtered donkeys were parasitologically examined for the existence of $S$. equina. Twenty-nine donkeys were infected with $S$. equina and 58 donkeys were non-infected. Collected worms were classified by morphological criteria according to Solusby (1982). The identified worms were individually washed several times in phosphate buffered saline (PBS), pH 7.2 then divided into 2 batches, one for preparation of crude somatic antigen and the other for the excretorysecretory antigen. CSS antigen was prepared according to Theodore \& Kaliraj (1990). Briefly, washed worms were homogenised in PBS pH 7.2 and centrifuged at $13000 \mathrm{rpm} / 30 \mathrm{~min}$ in a refrigerated micro-centrifuge. The supernatant was aspirated off and aliquots were stored at $20{ }^{\circ} \mathrm{C}$ until used. Also, ESS antigen was obtained using the method of Thilagavathy et al. (1990) with some modifications. Living washed adult worms were incubated in $4 \mathrm{~mL}$ PBS pH 7.2 with penicillin $(100 \mathrm{IU} / \mathrm{mL})$ and streptomycin (100 $\mathrm{IU} / \mathrm{mL}$ ) at $37{ }^{\circ} \mathrm{C}$ for 24 hours in a $5 \% \mathrm{CO}_{2}$ incubator. The buffer was collected then centrifuged at $10000 \mathrm{rpm}$ for $20 \mathrm{~min}$ in a refrigerated micro-centrifuge. The ESS antigen was dialysed. The obtained ESS antigen was frozen at $-20{ }^{\circ} \mathrm{C}$ until used. Total protein content of all prepared antigens (CSS and ESS) was estimated according to Lowry et al. (1951).

\section{Immunological assays}

TNF- $\alpha$ and IL- 4 concentrations in serum samples were measured by an equinespecific ELISA kit (WKEA MED Supplies). The concentrations of serum TNF$\alpha$ and IL- 4 were determined by comparing the samples OD to the standard curves.

IgG analysis was done by indirect ELISA optimised by serial checker board titration to the following setup according to Kaushal et al. (2009) with a slight modification. Ninety-six well micro-titre plates (Grienger, Germany) were individually coated with $100 \mu \mathrm{L}$ per well of each diluted antigen at concentrations of 4 and $6 \mu \mathrm{g}$ per well for CSS and ESS, respectively, in carbonate-bicarbonate buffer, $\mathrm{pH} 9.6$ and incubated at $37^{\circ} \mathrm{C}$ for $1 \mathrm{~h}$, then stored overnight at $4{ }^{\circ} \mathrm{C}$. The coated plates were blocked with $200 \mu \mathrm{L}$ per well of blocking solution ( $2 \%$ dry skimmed milk in PBS $-0.05 \%$ Tween 20) and incubated at $37{ }^{\circ} \mathrm{C}$ for $1 \mathrm{~h}$. Then, $100 \mu \mathrm{L}$ per well of serum sample diluted 1:200 was added to individual wells in duplicates and incubated for $2 \mathrm{~h}$ at $37^{\circ} \mathrm{C}$. Positive, negative and blank controls were included on each plate in duplicates. One hundred $\mu \mathrm{L}$ of HRP-conjugated goat antihorse IgG conjugate (Sigma, Aldrich, USA) diluted 1:2500 was added to each well and the plates were incubated for $1 \mathrm{~h}$ at $37{ }^{\circ} \mathrm{C}$. After that, the wells were incubated with $100 \mu \mathrm{L}$ of substrate solution 20 $\mathrm{mg}$ o-phenylenediamine dissolved in 50 $\mathrm{mL}$ substrate buffer, $\mathrm{pH} 5$ and $25 \mu \mathrm{L} \mathrm{30 \%}$ $\mathrm{H}_{2} \mathrm{O}_{2}$ ) for 10 minutes at $37^{\circ} \mathrm{C}$. The reactions were stopped with $100 \mu \mathrm{L}$ of stopping solution (5\% SDS) to each well and the optical densities (OD) were determined at $450 \mathrm{~nm}$ using an ELISA reader (BIO-TEK, INC., ELx, 800UV). A cut off value based upon $20 \%$ of the positive control serum was selected to discriminate between positive and negative tested sam- 
ples (Bauer et al., 2002). Antibodies percentage was calculated as $\mathrm{OD}(\%)=100 \times$ (Mean $\left.\mathrm{OD}_{\text {sample }}-\mathrm{OD}_{\text {negative control }}\right) /\left(\mathrm{OD}_{\text {posi- }}\right.$ tive control $\left.-\mathrm{OD}_{\text {negative control }}\right)$.

Sensitivity, specificity, positive predictive value, negative predictive value and apparent prevalence were calculated for each antigen according to Tabouret et al. (2001) and Bauer et al. (2002).

\section{SDS-PAGE and western blotting}

Both CSS and ESS were resolved on three separate $10 \%$ polyacrylamide gels under reducing conditions according to Laemmli (1970). Pre-stained molecular weights protein markers (Fermentas and Genedirex BLUltra, USA) were included on each gel. After electrophoresis, one gel was stained with coomassie brilliant blue R250 dye and the other two were transferred to 0.45 nitrocellulose membranes according to Towbin et al. (1979). Membranes were blocked for 1 hour in $1 \%$ dry skimmed milk dissolved in PBS pH 7.2, then probed overnight with control positive naturally infected and control negative sera at $1: 100$ in Tris-buffered saline (TBS) with $0.5 \%$ bovine serum albumin (BSA) against both antigens. The nitrocellulose strips were incubated with HRPconjugated goat anti-horse IgG conjugate at $1: 2500$ in $0.5 \% \mathrm{BSA} / \mathrm{TBS}$ buffer for $1 \mathrm{~h}$. The immunoreactive bands were developed by incubation of the blot in the substrate solution (1-chloronaphthol,
Sigma-Aldrich, USA - one tablet $30 \mathrm{mg} / 1$ $\mathrm{mL}$ methanol added to $10 \mathrm{~mL}$ methanol, $39 \mathrm{~mL}$ TBS and $30 \mu \mathrm{L} 30 \% \mathrm{H}_{2} \mathrm{O}_{2}$ ) for 5 $\min$.

\section{Statistical analysis}

Analysis of variance (ANOVA) was used to compare blood levels of TNF- $\alpha$ and IL4 in $S$. equina infected and non-infected donkeys. OD data were expressed as mean with standard error (mean \pm SEM) and analysed using chi-square test by Graph Pad Prism version 7. Differences were considered significant at $\mathrm{P}<0.05$ level.

\section{RESULTS}

\section{Immunological assays}

Current data revealed that both TNF- $\alpha$ and IL-4 levels in the blood of $S$. equina infected donkeys were significantly higher compared to the non-infected group $(\mathrm{P}<0.05$ and $\mathrm{P}<0.01$, respectively; Table 1). In the infected donkeys, blood level of IL-4 was significantly higher than TNF- $\alpha$ $(\mathrm{P}<0.01)$.

Necropsies results of slaughtered donkeys revealed that the prevalence of $S$. equina infection was $33.76 \%$. Results showed that CSS immunodiagnostic values of IgG were significantly higher by using CSS antigen $(369.70 \%)$ than with the ESS antigen $(175.97 \%, \mathrm{P}<0.05)$ (Ta-

Table 1. Blood levels $(\mathrm{ng} / \mathrm{mL})$ of tumor necrosis factor alpha and interleukin-4 in S. equina infected and non-infected donkeys. Data are presented as mean \pm SEM

\begin{tabular}{lcc}
\hline Parameter & $\begin{array}{c}\text { S. equina infected } \\
\text { donkeys }(\mathrm{n}=29)\end{array}$ & $\begin{array}{c}\text { Non-infected } \\
\text { donkeys }(\mathrm{n}=59)\end{array}$ \\
\hline Tumor necrosis factor-alpha & $10.184 \pm 1.09^{*} \mathrm{~A}$ & $7.294 \pm 0.41$ \\
Interleukin-4 & $17.292 \pm 1.68^{* * \mathrm{~A}}$ & $9.156 \pm 1.35$ \\
\hline
\end{tabular}

$* \mathrm{P}<0.05 ; * * \mathrm{P}<0.01 \mathrm{vs}$ non-infected animals; ${ }^{\mathrm{A}}$ Values in the same column are significantly different at $\mathrm{P}<0.01$. 
Table 2. Antibodies' optical density and diagnostic accuracy (\%) using different prepared S. equina antigens by ELISA

\begin{tabular}{lccc}
\hline & \multicolumn{2}{c}{ S. equina antigens } & Chi square \\
\cline { 2 - 3 } Diagnostic accuracy \% & $\begin{array}{c}\text { Crude somatic } \\
\text { S. equina }\end{array}$ & $\begin{array}{c}\text { Excretory secretory } \\
\text { S. equina }\end{array}$ & \\
\hline Antibodies OD & $369.70 \pm 14.6$ & $175.97 \pm 8.98$ & $<0.05$ \\
Apparent prevalence & 96.55 & 79.31 & $<0.05$ \\
Sensitivity & 35.10 & 32.70 & - \\
Specificity & 100 & 41.10 & $<0.05$ \\
Positive predictive value & 100 & 65.50 & $<0.05$ \\
Negative predictive value & 4 & 2.17 & - \\
\hline
\end{tabular}

ble 2). The ELISA results showed that the apparent prevalence of $S$. equina infection was significantly higher using CSS antigen $(96.55 \%)$ than ESS antigen (79.31\%) $(\mathrm{P}<0.05)$. However, there was no significant difference in sensitivity between CSS and ESS, $35.1 \%$ and $32.7 \%$, respectively, while the specificity was significantly higher using CSS (100\%) vs ESS (41.1\%) $(\mathrm{P}<0.05)$. In addition to these findings, higher positive predictive value percentages were achieved using CSS antigen $(100 \%)$ than with the ESS antigen $(65.5 \%)(\mathrm{P}<0.05)$. The negative predictive values were $4 \%$ and $2.17 \%$ for CSS and ESS antigens, respectively (Table 2).

\section{SDS-PAGE and western blotting profiles}

The coomassie stained SDS-PAGE and western blotting profiles of ESS and CSS antigens were resolved. The obtained results showed variations in protein bands between the prepared $S$. equina antigens. The ESS antigen showed 8 protein bands with molecular weights ranging from 180 to $17 \mathrm{kDa}$; however, the CSS exhibited 17 protein bands with molecular weights ranged from 273 to $17 \mathrm{kDa}$ (Fig. 1). On the other hand, immunogenic bands were detected from pooled sera of infected and non-infected donkeys against the $S$. equina antigens via western blotting (Fig.
2 and 3). The ESS antigen presented 6

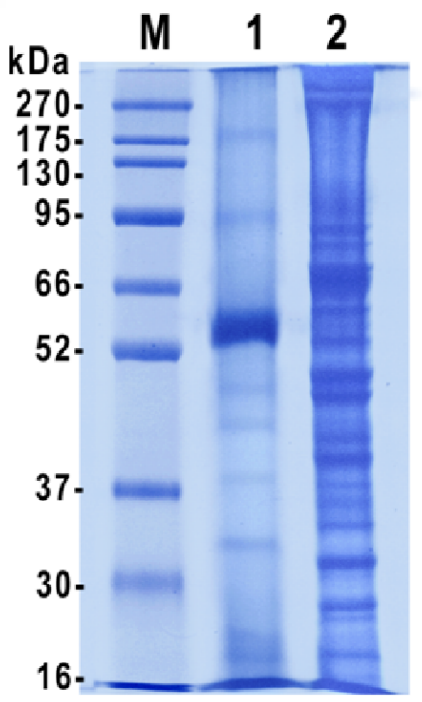

Fig. 1. Electophoretic protein profile of $S$. equina antigens: ESS (lane 1), CSS (lane 2), prestained molecular weight protein ladder (M).

immunoreactive bands at molecular weights ranging from 55 to $15 \mathrm{kDa}$, whereas the CSS antigen - 17 immunoreactive bands from 86 to $15 \mathrm{kDa}$ using infected pooled sera (Fig. 2). When pooled non-infected sera were used, only $6 \mathrm{im}$ munoreactive bands from 262 to $65 \mathrm{kDa}$ were recognised at higher molecular weights and 4 immunoreactive bands from 
260 to $102 \mathrm{kDa}$ with ESS and CSS antigens, respectively (Fig. 3).

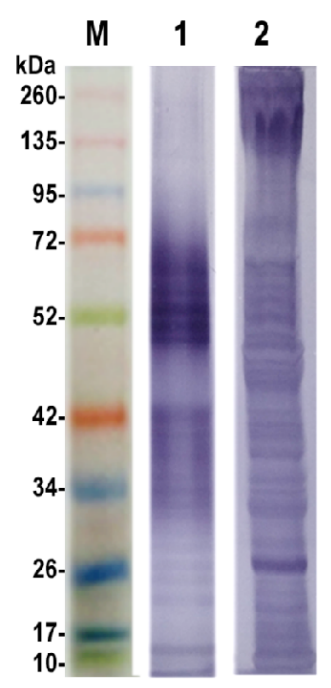

Fig. 2. Western blotting analysis of $S$. equina antigens: ESS (lane 1), CSS (lane 2) and prestained molecular weight protein ladder (M) against infected serum.

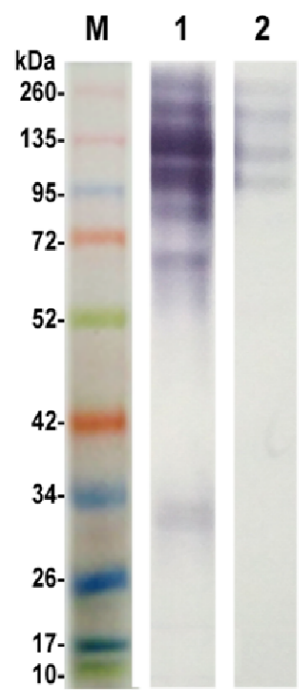

Fig. 3. Western blotting analysis of $S$. equina antigens: ESS (lane 1), CSS (lane 2) and prestained molecular weight protein ladder (M) against non-infected serum.

\section{DISCUSSION}

S. equina infection has been reported worldwide (Hornok et al., 2008; Suleiman et al., 2012). Our study revealed that $33.76 \%$ of the examined donkeys were infected with adult $S$. equina. This result differed from the stated percentage of $15 \%$ recorded by Oge et al. (2003) when looking for the existence of adult $S$. equina in slaughtered donkeys and horses in Turkey, while it was lower when blood samples were checked for microfilaria. However, the percentage was $4 \%$ in Turkey (Oge et al., 2003) and $9.2 \%$ in Hungary (Hornok et al., 2008) and in Iraq it reached 30.76\% (Suleiman et al., 2012).

Direct measurement of cytokine responses (TNF- $\alpha$ as Th1 and IL-4 as Th2 indicators) to $S$. equina infection was carried out initially to clarify immunological differences to obtain the most immunogenic agents responsible for the provoked immune response. In this study blood levels of TNF- $\alpha$ (Th1) and IL-4 (Th2) in $S$. equina infected donkeys were significantly higher compared to the noninfected group $(\mathrm{P}<0.05$ and $\mathrm{P}<0.01$ respectively). These results were in agreement with the studies of Wammes et al. (2012) and Kwarteng et al. (2016) concluding that $\mathrm{T}$ helper cells from the majority of $\mathrm{T}$ lymphocyte responses, following activation, differentiate into effector Th1 and Th2 phenotypes associated with the development of type- 2 cytokine immune responses and impairment of type- 1 cytokine production. However, in infected donkeys blood level of IL-4 was significantly higher than TNF- $\alpha(\mathrm{P}<0.01)$. The elevation in IL-4 levels might indicate that the animals were chronically infected. This result was in agreement with the previous studies of Sharma et al. (2005) and Wammes et al. (2012) in which the levels 
of IL-4, IL-5 and IL-10 increased in all chronic, microfilaraemic and endemic control cases. T-cells play a key role in regulating the balance between infection and disease, with Th1 and Th2 phenotypes being predominantly related to susceptibility and protection respectively (Carvalho et al., 2009). In contrast, in the early filarial infection there was an elevation in the rate of T cells expressing TNF$\alpha$ rather than IL-4 (Subash \& Nutman, 2003). Thus, filarial parasites could provoke early activation of Th1 cells which is important to understand the infection pathogenesis and the host-parasite relationships. In addition, the early $\mathrm{T}$ cell response to this parasite could show evidence about the host immune response manipulation to produce resistance against infection. The early immune response to the filarial parasite was predominated by early stimulation and production of T cells pro-inflammatory cytokines. This response could be the beginning of the acute filariasis and the formation of host resistance to the helminth infection (Subash \& Nutman, 2003). Monocytes and macrophages performed a major role in antigen processing and presentation by cytokines releasing such as IL-1 and TNF- $\alpha$. These cytokines activated $\mathrm{T}$ cells to stimulate clonal-proliferation induction. Although filarial-specific proteins have been produced, the host immune responses to these antigens and their interaction with the monocytes were not well defined yet (Uma et al., 1999).

Furthermore, the IgG concentrations in collected sera were measured with a focus on the diagnostic accuracy of the antigens used along with electrophoretic protein profile and $\operatorname{IgG}$ reactivity via western blotting. Our results revealed that immunodiagnostic values of IgG were significantly higher using CSS antigen
(369.70\%) than ESS antigen (175.97\%, $\mathrm{P}<0.05)$. Also, the prevalence of $96.55 \%$ was combined with highest specificity and positive predictive value - $100 \%$ each achieved with the CSS antigen. This finding could be returned to the immune reactive band at $28 \mathrm{kDa}$ which was the most prominent in its binding reactivity. In addition, a higher number of reactive CSS antigen protein bands binding to $\mathrm{IgG}$ were detected by western blot than those presented by the ESS antigen. This finding might be explained by the complex protein nature of crude antigenic materials of adult $S$. equina, as well as the persistence of the adult form, and its capability of immune evasion may provide a good chance for the production of IgG against the epitopes of this parasitic macromolecule (Tizard, 2000; Kaushal et al., 2009). Additionally, host immunity is raised against a common variant, one or more newly expressed variants can arise so the host must then build another specific immune response of $\mathrm{IgG}$ and increase its titre against the new variant form (Frank, 2002). This suggestion comes along with the previously mentioned data that excretory secretory antigens of Setaria spp. are formed in the uterus during the embryonic development and released during hatching, thus the antigenic material of ESS products during the total time of infection is less (Decruse \& Kaleysaraj, 1988; Bahgat et al., 2011). The current data of ESS and CSS immunogenic reactive bands appeared against infected donkeys' sera agreed with the findings of Bahgat et al. (2011) in which reactive bands were detected at molecular weights 200, 100.5, 93.3, 66.2, 60, 33.6, 27.8 and $17 \mathrm{kDa}$ after using crude male and female $S$. equina antigens and their excretory-secretory antigens against clinically different human sera. Also, Maizels et al. (1995) and Oge 
et al. (2005) reported that the IgG4 antibodies present in filarial sera reacted preferentially with parasite antigen of low molecular weight pattern on using $S$. digitata and Dirofilaria immitis antigens, respectively. However, Dalai et al. (1998) and Mohanty et al. (2006) indicated that endemic and chronic subjects do not make detectable IgG4 antibodies against the 14to $20-\mathrm{kDa}$ antigens. Hence, the CSS antigen could be used as a promising antigen in serological diagnosis of $S$. equina infection by assaying the total circulating $\mathrm{IgG}$ in the collected sera as part of the performed immunological studies. Our current study explored the impact of cytokine responses (TNF- $\alpha$ and IL-4) in $S$. equina infection where both TNF- $\alpha$ and IL-4 found in the serum levels of infected donkeys were significantly higher than the non-infected group. Further studies were recommended to investigate the differences between $S$. equina acute and chronic infection and to elucidate their effect on the immune response modulation.

\section{ACKNOWLEDGEMENTS}

This work was supported by the National Research Centre fund in Egypt (grant number: p101211). Authors gratefully acknowledge Paul Lacy, Animal Diseases Research Unit, Agricultural Research Services, United States Department of Agriculture, Pullman, USA for his support in English editing of the manuscript.

\section{REFERENCES}

Abdel-Latif, M. \& T. Sakran, 2016. Detection for cross-reactive proteins in filarial worm Setaria equina, MCF-7 human breast cancer, and Huh-7 hepatoma cells. Journal of Immunoassay \& Immunochemistry, 37, 6.
Bahgat, M. M., A. H. Saad, G. A. El-Shahawi, A. M. Gad, R. M. Ramzy, A. Ruppel \& M. Abdel-Latif, 2011. Cross-reaction of antigen preparations from adult and larval stages of the parasite Setaria equina with sera from infected humans with Wuchereria bancrofti. Eastern Mediterranean Health Journal, 17, 679-686.

Bauer, C., G. Steng, F. Prevot \& P. Dorchies, 2002. Seroprevalence of Oestrus ovis infection in sheep in Southwestern Germany. Veterinary Parasitology, 110, 137-143.

Carvalho, L., J. Sun, C. Kane, F. Marshall, C. Krawczyk \& E. J. Pearce, 2009. Review series on helminthes, immune modulation and the hygiene hypothesis: Mechanisms underlying helminthes modulation of dendritic cell function. Immunology, 126, 28 34.

Dalai, S. K., D. Das \& S. K. Kar, 1998. Setaria digitata adult 14 -to $20-\mathrm{kDa}$ antigens induce differential Th1/Th2 cytokines responses in the lymphocytes endemic and asymptomatic microfilariae carries in bancroftian filariasis. Journal of Clinical Immunology, 18, 114-123.

Decruse, S. W. \& R. Kaleysaraj, 1988. Excretory secretory material from different sites of female reproductive tissue of filarial parasite Setaria digitata. Indian Journal of Experimental Biology, 26, 781-783.

Frank, S. A., 2002. Immunology and Evolution of Infectious Disease. Princeton (NJ), Princeton university press.

Hillyer, L., G. Coles \& T. Randle, 2001. Setaria equina in the UK. The Veterinary Record, 149, 464.

Hornok, S., C. Genchi, C. Bazzocchi, E. Fok \& R. Farkas, 2008. Prevalence of Setaria equina microfilaraemia in horses in Hungary. The Veterinary Record, 161, 814816.

Kaushal, N. A. R Hussain \& E.A. Ottesen, 1984. Excretory-secretory and somatic antigens in the diagnosis of human filariasis. Clinical and Experimental Immunology, 56, 567-576. 
Kaushal, N. A., N. Srivastava, H. Mustafa, A. Tandon, S. K. Singh \& D. C. Kaushal, 2009. Isolation of an antigen fraction from Setaria cervi adults having potential for immunodiagnosis of human filariasis. Immunological Investigations, 38, 749-761.

Kwarteng, A., S. T. Ahuno \& F. O. Akoto, 2016. Killing filarial nematode parasites: Role of treatment options and host immune response. Infectious Diseases of Poverty, 5, 86.

Laemmli, U. K., 1970. Cleavage of structural proteins during the assembly of the head of bacteriophage T4. Nature, 227, 680-685.

Lowry, O. H., N. J. Rosebrough, A. B. Farr \& R. J. Randall 1951. Protein measurement with the folin-phenol reagent. Journal of Biological Chemistry, 193, 265-275.

Mahmoud, A. E., 1998. Laboratory diagnosis of filariasis in Assiut Governorate. M. V. Sc. thesis, Faculty of Veterinary Medicine, University of Assiut.

Maizels, R. M., E. Sartono, A. Kurniawan, F. Partono, M. E. Selkirk \& M. Yazdanbakhsh, 1995. T-cell activation and the balance of antibody isotypes. Parasitology Today, 11, 50-56.

Marzok, M. A. \& A. Y. Desouky, 2009. Ocular infection of donkeys (Equus asinus) with Setaria equina. Tropical Animal Health and Production, 41, 859-863.

Mohanty, B. P., S. K. Dalai \& S. K. Kar, 2006. IgG4-reactive low molecular weight antigens from Setaria digitata adult parasites have immunodiagnostic potential in lymphatic filariasis. Current Science, 91, 1221-1225.

Njenga, S. M., C. N. Wamae, C. S. Mwandawiro \& D. H. Molyneux, 2007. Immunoparasitological assessment of bancroftian filariasis in a highly endemic area along the River Sabaki, in Malindi district, Kenya. Annals of Tropical Medicine and Parasitology, 101, 161-172.

Oge, H., S. Oge, A. Yildirim, F. Kircali \& M. Kara, 2005. Immunoblotting analysis of somatic components of Dirofilaria immitis. Parasite, 12, 179-182.
Oge, S., H. Oge, A. Yildirim \& F. Kircali, 2003. Setaria equina infection of Turkish equines: Estimates of prevalence based on necropsy and the detection of microfilaraemia. Annals of Tropical Medicine and Parasitology, 97, 403-409.

Rhee, J. K., E. Y. Choi, B. K. Park \& B. G. Jang, 1994. Application of scanning electron microscopy in assessing the prevalence of some Setaria species in Korean cattle. Korean Journal of Parasitology, 32, $1-6$.

Sharma, A., M. Rajappa, P. L. Mehndiratta \& A. Saxena, 2005. Increased levels of interleukin- 4, 5 and 10 and decreased levels of interleukin-2 and interferon-gamma in lymphatic filariasis. Biomedical Research, 16, 33-39.

Simonsen, P. E., M. N. Malecela, E. Michael \& C. D. Mackenzie 2008. Lymphatic filariasis research and control in Eastern and Southern Africa. DBL - Centre for Health Research and Development.

Solusby, E. J. L., 1982. Helminths, arthropods and protozoa of domesticated animals, Seventh Edn. Bailliere Tindall, London.

Subash, B. \& T. Nutman, 2003. Proinflammatory cytokines dominate the early immune response to filarial parasites. The Journal of Immunology, 171, 6723-6732.

Suleiman, E. G., S. S. Aghwan \& O. M. AlIraqi, 2012. Detection of microfilaria infection in horses in Mosul city. Iraqi Journal of Veterinary Science, 26, 23-26.

Tabouret, G., F. Prevot, J.P. Bergeaud, P.h. Dorchies \& P. Jacquiet, 2001. Oestrus ovis (Diptera: Oestridae): Sheep humoral immune response to purified excreted/secreted salivary gland $28 \mathrm{KDa}$ antigen complex from second and third instar larvae. Veterinary Parasitology, 101, 53-66.

Theodore, J. G. \& P. Kaliraj, 1990. Isolation, purification and characterization of surface antigens of the bovine filarial parasite $\mathrm{Se}$ taria digitata for the immunodiagnosis of bancroftian filariasis. Journal of Helminthology, 64, 105-114. 
Thilagavathy, A. H., B. Prabha \& R.K . Raj, 1990. Excretory secretory antigens of filarial parasite Setaria digitata. Indian Journal of Experimental Biology, 28, 291-292.

Tizard, I. R., 2000. Veterinary Immunology: An Introduction, Sixth edn, W. B. Saunders Company.

Towbin, H., T. Staeheline \& J. Gordon, 1979. Electrophoretic transfer of proteins from polyacrylamide gels to nitrocellulose sheets: Procedure and some applications. Proceedings of the National Academy of Sciences, 76, 4350-4354.

Uma, R., E. Devarajan, B. N. Rangarajan, J. Kunthala \& K. Perumal, 1999. Proinflammatory cytokines secreted by monocytes of filarial patients. Microbiology, 3, 279-283.

Wammes, L. J., F. Hamid, A. E. Wiria, H. Wibowo, E. Sartono, R. M. Maizels, H. H. Smits, T. Supali \& M. Yazdanbakhsh, 2012. Regulatory $\mathrm{T}$ cells in human lymphatic filariasis: Stronger functional acti- vity in microfilaremics. PLOS Neglected Tropical Diseases, 6, 1655.

Paper received 17.04.2017; accepted for publication 05.06.2017

\section{Correspondence:}

Amira H. El Namaky, PhD

Department of Parasitology and

Animal Diseases,

National Research Centre,

El-Bohouth Street, Dokki,

Postal Box 12622, Giza, Egypt.

tel: +201006340534

fax: 00233370931

e-mail: amiraelnamaky@gmail.com 